\title{
Curriculum Complexity Based Model of Blended Learning
}

\author{
M. Mubasher Hassan ${ }^{1}$ and Tabasum Mirza ${ }^{2}$ \\ Department of Information Technology and Engineering $(\text { ITE })^{1}$ \\ Baba Ghulam Shah Badshah University (BGSBU), Rajouri (J\&K), India \\ Department of Computer Science, School Education ${ }^{2}$ \\ Government of Jammu and Kashmir, J\&K, India \\ mubasher2003@gmail.com ${ }^{1}$,tabasum.mirza@gmail.com ${ }^{2}$
}

\begin{abstract}
In view of growing trends towards the use of e-learning on ICT platform, there is structuring of various approaches of on-line learning. The Blended learning is one of the strategic approach, where the traditional classroom method and e-learning is taken together for much better, fast and effective teachibg-learning processes. In this paper, the conceptual model based on curriculum complexity is devised, where the e-learning part is taken on board. While developing the course curriculum, some portion is identified to be taught by elearning approach, so that the concept of Blended learning is implemented by all means. Although, this restraints flexibility of a learner to some extent, but on the other hand people start learning using various e-learning approaches and thereby Blended learning is executed in substantial manner.
\end{abstract}

Index Terms - Blended learning, E-learning, Traditional classroom learning, curriculum complexity and ICT.

\section{INTRODUCTION}

Improvement in internet connectivity and availability of high bandwidth has made it possible to equip schools even in remote areas with new teaching learning techniques making use of technology. In initial phase of establishment ICT labs are being setup in nearly all secondary schools in India which was a promising initiative to address the goals of expansion in education using technology. The second step towards achievement of technology driven education is to make use of the ICT laboratories to deliver high quality educational content. This can be done with the help of e-learning, which refers to utilization of electronic devices and technologies to deliver education outside the traditional class rooms. Elearning can use internet as resource to deliver knowledge to the learner, but can include other technologies as well. It has already been accepted as driving trend in education in the modern era. It is most popular in higher education and is taking the space in the school education as well. Generally, in e-learning whole of the course is delivered on line. But, it can be used as complementary teaching mechanism along with traditional class room teaching. Free online education is gaining popularity in present era of technology in key subjects like science, mathematics, engineering, business and management providing opportunities to young generation to reach out for quality education on their own. But there is lack of formal system of education in this regard. E-learning is learner directed learning (LDL), as it offers flexibility and portability to the learner. It is tailored for everyone and is accessible $24 \times 7$. It can be used to impart training by transferring knowledge and skills via the internet medium. The lectures available on line
Can be repeated as many times as the learner desires and thereby the learning is done as the ease of a learner rather than according to the speed of the whole class. The secondary storage devices like external/internal hard disks, Optical disks, mass storage devices and pen drives are used for archiving the content. The commonly techniques of e-learning are webcasting and web conferencing[1].

\section{MAJOR BENEFITS OF E-LEARNING}

- Learner centric learning

- Saves time of travelling and reaching to the class room destination

- Affordable and cost effective

- Fast mode of learning

- Flexible and portable mode of learning

- Simple, easy and effective mode of learning

- Prompt, dynamic and fast environment

- Availability of updated content

- Collaborative learning system

- Highly scalable

- Better evaluation and assessment

- Consistent

- Paperless and thereby environment friendly

- Versatile

- Available to every one

- Ease of accessibility

- Reaching the unreached.

- Enjoyable

- Allows people with physical disabilities to compete in a similar environment. 


\section{Available online at www.ijrat.org}

- Multiply efforts of a teacher in preparation

\section{LIMITATIONS}

In spite of all the advantages, e-learning has some limitations also and are as under:

- Lack of personal touch: Nothing can replace the human contact, so lack of human touch in e-learning makes it surreal

- Lack of control

- Weak self regulation

- Poor achievement of moral values

- The credibility of traditional class teacher gets effected

- No face to face interaction

- Slow evolution

- Technological failures: malfunction of devices, power failure, bandwidth issues, etc.

- Lack of electricity

- Internet connectivity issues

- Procrastination in learning on the part of learner

- Less connected to physical libraries and laboratories.

- Design limitations

- Poor monitoring and lack of academic honesty

- Deluge of less useful information.

- Negative perception of techno phobic people especially older generations.

- Intellectual property rights issues[2].

\section{CONCEPT OF BLENDED LEARNING}

After analyzing pros and cons of e learning it is imperative to use teaching approach which complements traditional classroom teaching with elearning rather than replacing it entirely by e-learning. This approach is called blended approach of learning and it combines strengths of both the traditional as well as e-learning approaches[2]. The blended approach of teaching learning is a collaborative formal approach of learning (see fig.1and 2.). It provides the advantage of proper regulation along with flexibility and portability to certain extent[3]. The main idea is to use e-learning to teach/learn complex topics which are better understood by visual learning. It is an established fact that the human brain can easily understand and remember visual information, videos and images and these can be used to easily grasp and remember complex information while as text is difficult to understand and remember in complex topics. The blended approach will transform elearning to a new level, making it a formal system of learning by combining it with classroom teaching. for class

This method of learning is emerging and is gradually taking the space in institutions of learning, especially

in higher learning, as it is said to be well controlled and partially supervised mode of learning.

What if every child has its own teacher?

The blended learning is formal education learning in supervised environment in guidance of teachers and away from home, where more than $25 \%$ of the curriculum is taught online. The role of teachers is redefined in blended learning as behavior specialist, instructor facilitator, advisor and teacher. The teacher will manage behavior of students and monitor their progress to facilitate learning and providing face to face support. But in spite of supervision and monitoring by teachers, students can control their learning to a large extent and get engaged and enjoy learning at their own pace and time. When done in right way, it can contribute to enjoyable extent of learning, as students learn mostly by active work and not by passive listening[4].

In conventional classroom teaching, the teacher is not able to get complete information of a student and or the proper judgment of a teacher on a student is weak and might be strong with time.

It is a well established research fact, that blended learning is more effective approach of achieving the learning goals than traditional and fully online approach[5].
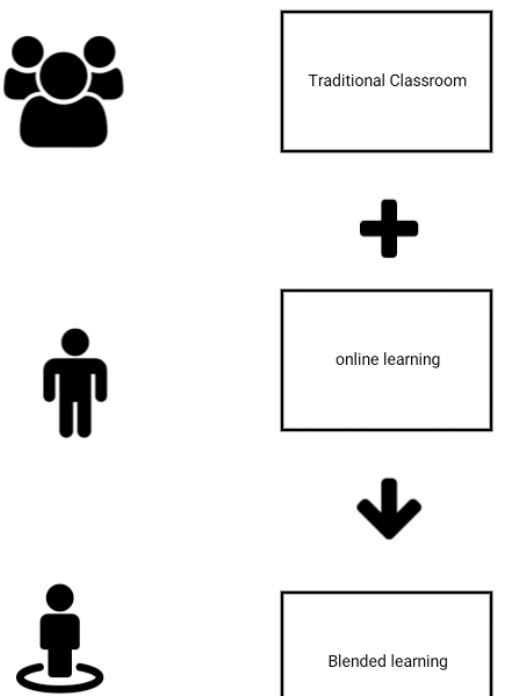

Blended learning

Fig.1. Blended Learning 


\section{Available online at www.ijrat.org}

\section{MODELS OF BLENDED LEARNING}

a. Rotational Model: There is a rotation between different modalities i.e classroom teaching and online teaching based on schedules.

b. Flex Model: The schedule is customized at discretion of a student to supplement classroom teaching. Online learning is the primary method for learning, here the teachers provide the interactive support and material is primarily delivered online.

c. Alacarte Model: It is not a whole school experience, the students learn online within the school or at off campus and teachers provide onsite support and learning is mainly learner directed and independent.

d. Virtual class room: It provides the whole school experiences by remotely using online learning in traditional class room and has fixed schedules and mostly whole of the course or degree is delivered remotely. But with the support of face to face instructor[6].

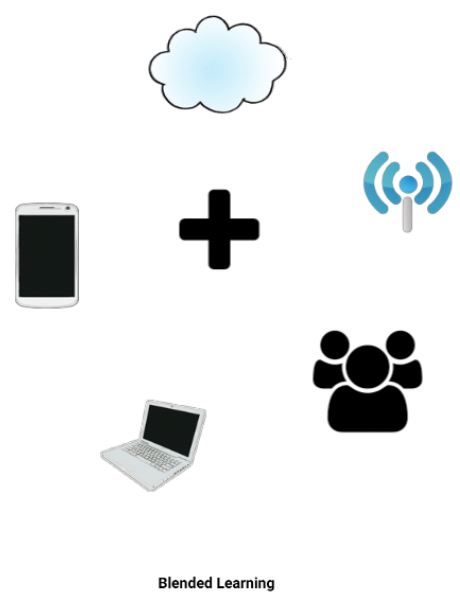

Fig.2. Overview of Blended Learning

\section{CONCEPTUAL FRAMEWORK:}

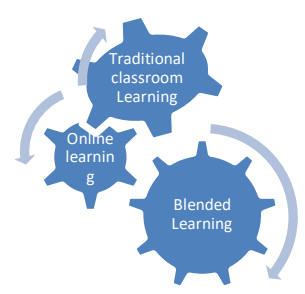

Fig.3. Curriculum complexity based model
We are proposing a model that is based on curriculum complexity (see fig. 3 and 4). In this model team of subject experts will divide the curriculum into portions suitable for online learning and traditional classroom learning. The subject topics well suited for online learning will be taught online and topics suitable for face to face learning will be delivered traditionally. Experts will take into account the capability of the learners or students and their pace of learning also for customization of curriculum .online learning can also be used to supplement rather replace classroom learning for certain topics which students are not able to understand properly by traditional classroom teaching methods .Curriculum customization is the critical step in this model and can be improved by taking students into confidence and by taking inputs from preliminary student assessment scores to test their preliminary knowledge. Assessment of learner participation and feedback from learners can result in instruction well suitable for independent mode of learning. Student assessment can be achieved by conducting routine performance tests, grading and scoring methods to assess success of teaching learning methods used. Student participation can be assessed by using student login methods.

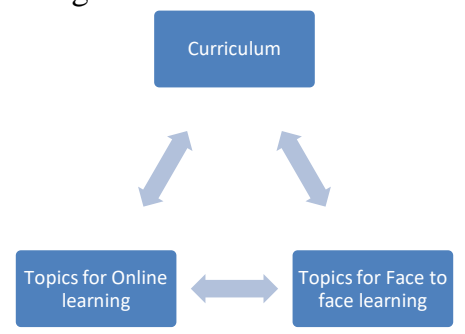

Fig.4. Complexity Based Model of Blended learning

This model combines different methods of offline and online learning to create self paced, self directed, customized and flexible method of learning suitable for particular curriculum and target learners [7]. The model will give learners sense of independence and autonomy but with proper regulation and discipline. Role of teachers will change and teachers will act as mentors and judges to check learning progress of students and assess success of teaching methods used. The learning environment will be properly supervised by teachers to ensure proper discipline. Teachers will also monitor student participation and guide learners towards learning as well as providing interactive 
support to students. The students will provide time to time feedback for customization of schedules, subject topics and schedule of discussions etc.

\section{CONCLUSION}

The customization of curriculum is the main challenge in this method and success of the model depends upon the customization of curriculum. The subject experts should take into account complexity of topics with respect to learners and their preliminary knowledge and pace of learning. The revision of curriculum may take efforts and time but can result in strong and learner directed curriculum suitable for blended learning. The role of teacher changes from teaching to mentorship and judge. In other way, the responsibilities of teacher are shifted to another new level, where he/she has to guide, monitor and assess the progress of a learner without breaching the autonomy and flexibility of a learner much. The role of student changes from passive learner to active participant in learning environment that is learner directed, self paced but supervised by teachers. By fixing the responsibility on learner with regard to completion or learning of identified portion of curriculum by e-learning means is the crux of this paper.

\section{REFERENCES}

[1] B. Gilbert, "Online Learning Revealing the Benefits and Challenges," 2015.

[2] T. Nguyen, "The Effectiveness of Online Learning : Beyond No Significant Difference and Future Horizons," vol. 11, no. 2, pp. 309-319, 2015.

[3] A. L. Nazarenko, "Blended Learning vs Traditional Learning: What Works? ( A Case Study Research )," Procedia - Soc. Behav. Sci., vol. 200, no. October, pp. 77-82, 2015.

[4] B. Güzer and H. Caner, "The past, present and future of blended learning : an in depth analysis of literature," Procedia - Soc. Behav. Sci., vol. 116, pp. 4596-4603, 2014.

[5] J. H. Rivera, "The Blended Learning Environment: A Viable Alternative for Special Needs Students," vol. 5, no. 2, pp. 79-84, 2017.

[6] Y. E. Campus, “A BLENDED LEARNING MODEL,” no. July, pp. 78-97, 2010.

[7] Blended Learning :How to integrate online and traditional Learning by Kaye Thorne-2003 